University of Nebraska - Lincoln

DigitalCommons@University of Nebraska - Lincoln

U.S. Environmental Protection Agency Papers

U.S. Environmental Protection Agency

1982

\title{
Vegetative Delineation of Coastal Salt Marsh Boundaries
}

H. Peter Eilers

California State University - Fullerton

Alan Taylor

Oregon State University

William Sanville

United States Environmental Protection Agency

Follow this and additional works at: https://digitalcommons.unl.edu/usepapapers

Part of the Civil and Environmental Engineering Commons

Eilers, H. Peter; Taylor, Alan; and Sanville, William, "Vegetative Delineation of Coastal Salt Marsh Boundaries" (1982). U.S. Environmental Protection Agency Papers. 68.

https://digitalcommons.unl.edu/usepapapers/68

This Article is brought to you for free and open access by the U.S. Environmental Protection Agency at DigitalCommons@University of Nebraska - Lincoln. It has been accepted for inclusion in U.S. Environmental Protection Agency Papers by an authorized administrator of DigitalCommons@University of Nebraska - Lincoln. 


\title{
Vegetative Delineation of Coastal Salt Marsh Boundaries
}

\author{
H. Peter Eilers \\ California State University, Fullerton
}

\author{
Alan Taylor \\ Oregon State University, Corvallis

\section{William Sanville} \\ United States Environmental Protection Agency, Corvallis, Oregon
}

\section{Introduction}

Two decades of intensive research following the suggestions of Odum (1961) and the work of Teal (1962) have firmly established positive values for undisturbed coastal salt marshes. These intertidal wetlands are noted for high macrophyte production and for export of energy-rich organic detritus and dissolved organic carbon to estuarine waters. They serve as juvenile fish and wildlife habitats, water purifiers, and buffers to erosion of sediment.

Concurrent with increased awareness of salt marsh values and potentials, however, has been the rapid conversion of coastal marsh to urban, industrial, and agricultural uses through diking, filling, and construction activities (Darnell 1976). Recent federal legislation is designed to retard these alterations and thereby protect the nation's remaining wetland resources. Most notable are the Federal Water Pollution Control Act Amendments of 1972 and 1977 (Water Act) which, in Section 404 , establish a permit review process to regulate dredge and fill projects. 
To implement Section 404 requires that those involved in the permit review: (1) identify wetland, and (2) determine wetland boundaries. Yet, while wetland may frequently be identified by noting the presence of standing water and plants adapted to saturated soil conditions, the determination of the upper limit is often difficult. Instead of exhibiting a sharp break, the characteristics of wetland are more likely to gradually shift to those of upland along a transition. In salt marsh, the influence of the tide diminishes with increasing surface elevation, soils become better drained, and vegetation gradually changes. An ecotone with interdigitation of marsh and upland species occurs between the two systems (Figure 1).

To better understand the nature of the marsh-upland ecotone and to develop methods of delineating a legally defensible intertidal salt marsh boundary, the U.S. Environmental Protection Agency, in conjunction with the U.S. Army Corps of Engineers, began a major research effort in 1975. After three pilot projects were completed (National Ocean Survey 1975, Frenkel and Eilers 1976, Jefferson 1976), four groups were funded to investigate transition zones and upper limits. They covered salt marshes along the coasts of California (Harvey et al. 1978); Oregon and Washington (Frenkel et al. 1978); Alaska (Batten et al. 1978); Delaware, Maryland, Virginia, and North Carolina (Boon et al. 1978). The reports provide a floristic description of marsh-upland ecotones and identify approaches to boundary determination based on " egetation.

The purpose of this paper is to: (1) evaluate the methods used by these researchers, (2) present alternative methods, and (3) recommend approaches to wetland boundary delineation based on vegetation. The methods presented are applicable to wetland-upland boundary determination in general, not exclusively to salt marshes. However, we do acknowledge that vegetation should not be the only criteria considered. The best approach will likely incorporate an analysis of vegetation, soil, and hydrology. The methods considered here are a first approximation, but, as our knowledge of physical factors across the wetland-upland ecotone increases, methods for defining boundaries will be refined.

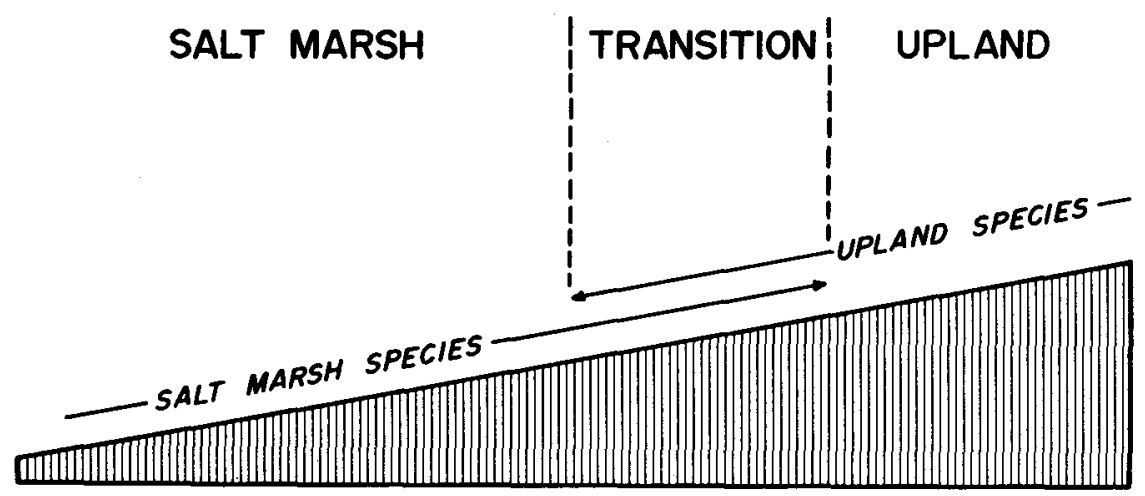

Figure 1. The transition from salt marsh to upland is often a zone of variable width with salt marsh and upland plant species. 


\section{Methods For Boundary Determination}

The methods of determining wetland boundaries to be evaluated range from those that have little quantitative data and emphasize indicator species to those that require classification of all plant species recorded and intensive quantitative treatment. First, we consider the less quantitative approach favored by Batten et al. (1978); then the more quantitative methods of other researchers. To this we add other quantitative approaches.

\section{Indicator Species}

Batten et al. (1978) investigated Alaska coastal salt marshes and collected information on plant species percent cover from quadrats located along the elevation gradient between marsh and upland. Based on these data and knowledge of plant species habitat preference, they developed lists of indicator species that signal the shift from salt marsh to terrestrial upland or freshwater marsh. The lower limit of the transition zone (LTZ) was established at the point where species "abundant" in upland or freshwater wetland first become "abundant" in the marsh. The upper limit of marsh (ULM) was set at the point where all the species characteristic of the vegetation type bordering the marsh were present in "appropriate amounts." No definition of "abundant" or "appropriate amounts" is given and, thus, establishing an actual boundary in the field using this approach would be subjective and ill-suited to situations involving legal scrutiny.

\section{Five Percent}

The initial approach of Boon et al. (1978) and Harvey et al. (1978) was similar to that above but included boundary delineation. Following acquisition of plant cover estimates from marsh to upland, a "five percent" method was used to define the upper limit of the transition zone as the point at which the amount of ground coverage by upland plants is at least five percent and is contiguous with the upland proper (Boon et al. 1978). The lower transition limit was defined similarly-upland plant coverage less than five percent. Plants were classified as to marsh, transition, upland (Boon et al. 1978) or marsh, upland, non-indicator (Harvey et al. 1978), and results were presented graphically. Harvey et al. used the following procedure: (1) when a five percent cover of the appropriate type (either marsh or upland) occurred in a quadrat with no trace in the adjacent, more distal quadrat, the quadrat with five percent cover was marked as the transition; (2) if the adjacent quadrat distal to the five percent cover plot had a trace of the vegetation type in question, the adjacent quadrat was marked as the transition limit; (3) if two plots in sequence had a trace of either vegetation type, the more distal quadrat was marked as the limit; (4) if the five percent cover level fell between two quadrats, the limit was located by interpolation; (5) if no overlap of upland and marsh species occurred either due to bare ground and/or cover by non-indicator species, a point midway between quadrats in which each type was represented was chosen (Figure 2). 

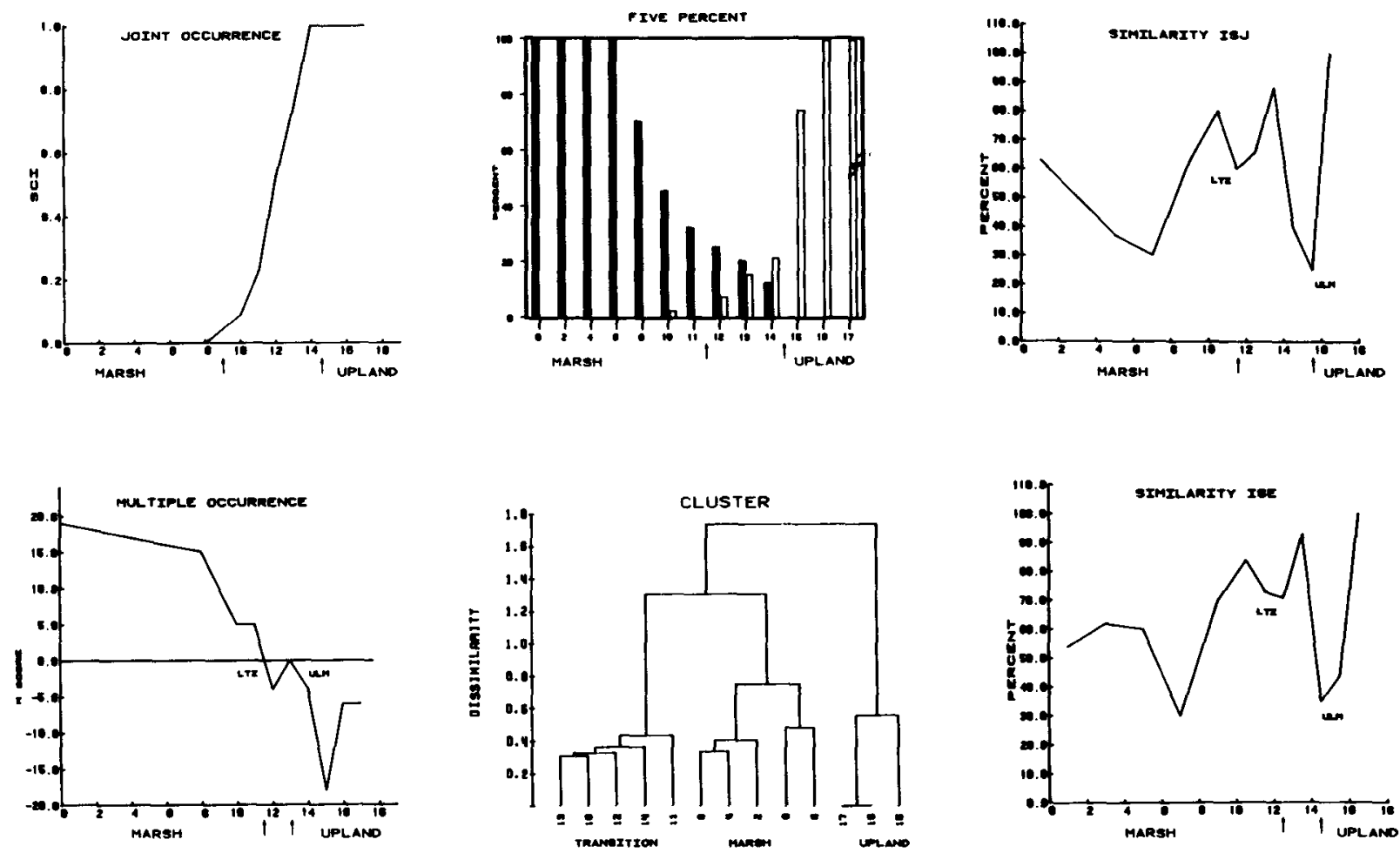

Figure 2. Lower limit of the transition zone (LTZ) and upper limit of marsh (ULM) for transect 0105 (Coquille Estuary, Oregon) as determined by six methods. Data from Frenkel et al. (1978). 


\section{Joint Occurrence}

After applying the five percent method, Harvey et al. (1978) sought a "quicker, easier, but equally accurate approach." Their choice was a modification of Fager's (1957) measure of joint occurrence,

$$
I_{M U}=\frac{2 J}{n M+n U},
$$

where, for any single quadrat, $J$ is the number of joint occurrences of marsh and upland species, $n M$ is the number of marsh species, and $n U$ is the number of upland species. Non-indicator species were disregarded.

Plotting $I_{M U}$ for quadrats along a transect shows a series of zeros for pure wetland, because there are no joint occurrences, followed by a rise to a peak in the transition and a fall to zero again in pure upland. In practice, however, Harvey et al. (1978) found it difficult to interpret such a graph when natural or man-made "patchiness" was present. This problem was largely eliminated by computing a standardized index (SI) then a standardized cumulative index (SCI) for each quadrat:

$$
\text { SI } i=\frac{I_{M U_{i}}}{\sum_{i=1}^{n} I_{M U_{i}}} \text { and } \mathrm{SCI}_{i}=\sum_{i=1}^{Q} S I_{i},
$$

where $n$ is the total number of quadrats and $Q$ is the quadrat for which $\mathrm{SCI}$ is computed. After plotting SCI values, Harvey et al. (1978) identified the lower and upper limits of the transition as $0.5 \mathrm{~m}$ above the rise of the data line from the abscissa and $0.5 \mathrm{~m}$ above $\mathrm{SCI}=1.0$, respectively (given $1 \mathrm{~m}$ distance between sample quadrats or one-half the distance if greater than $1 \mathrm{~m}$ ) (Figure 2). Close agreement between the SCI and the five percent method transition boundaries was observed.

\section{Multiple Occurrence}

Frenkel et al. (1978) analyzed species distribution patterns to develop four species categories-low marsh, high marsh, non-indicator, and upland-and computed a score for quadrant data collected along transects between marsh and upland. The "multiple occurrence method" (MOM) score (M) required the assignment of a weighting coefficient:

$\begin{array}{lc}\text { Species Type } & \text { Weighting Coefficient } \\ \text { Low marsh } & 2 \\ \text { High marsh } & 1 \\ \text { Upland } & -2 \\ \text { Non-indicator } & 0\end{array}$

The quadrat score was calculated as:

$$
\mathbf{M}=\sum_{i=1}^{n} W_{i} C_{i},
$$

where $W_{i}$ is the weighting coefficient for species $i, C_{i}$ is cover value for species $i$, 
and $n$ is total number of species in the quadrat sample. Cover values were after Daubenmire (1959): $0-5$ percent $=1,5-25$ percent $=2,25-50$ percent $=3,50$ 75 percent $=4,75-95$ percent $=5,95-100$ percent $=6$. Species present but with negligible cover were disregarded.

Positive $M$ values were interpreted as marsh, the upper limit of marsh was defined as $\mathbf{M}=0$, and $\mathbf{M}<0$ denoted upland. However, further interpretation was necessary because $M$ values did not always descend to a single $M=0$ and thereafter remain negative. Two additional cases were noted. One contained more than one $\mathbf{M}=\mathbf{0}$ in succession, and the other $\mathbf{M}$ scores alternated above and below zero. In both cases, the portion of the transect between first and last $\mathbf{M}=0$ were considered the transition zone and the upper limit of marsh was placed midway through this zone. In our interpretation of this method we assigned the upper limit of the transition zone as the ULM and combined high and low marsh with a weighting coefficient of 2 . The latter modification was considered to more accurately differentiate marsh and upland (Figure 2).

\section{Cluster}

If marsh and upland are floristically different, cluster analysis (Boesch 1977) of quadrat data collected along transects between the two systems might be used to identify wetland limits. Wuch an approach would have the advantage of not requiring preclassification of plant species into "marsh," "upland," "non-indicator." We chose the Bray-Curtis dissimilarity measure (Clifford and Stephenson 1975),

$$
D j k=\frac{\sum_{i=1}^{n} x_{i j}-x_{i k}}{\sum_{i=1}^{n}\left(x_{i j}+x_{i k}\right)},
$$

where $x$ is cover value for species $i$ in quadrats $j$ and $k$, and $n$ is the total number of species. A "flexible" fusion strategy with Beta $=-0.25$ (Boesch 1977) was utilized and the results displayed in a dendrogram with quadrat clusters forming at decreasing levels of dissimilarity (Figure 2). The upland cluster was identified as that containing the highest numbered quadrats (when quadrats were numbered from wetland to upland). The upper limit of marsh was interpreted as being half the distance on the transect between the lowest numbered member of the upland cluster and the highest numbered member of the lowest group of quadrats. This second group was identified as "transition" if three or more clusters were present.

\section{Similarity ISJ and ISE}

By computing the level of similarity in species content of adjacent quadrat samples along a transect and graphing these values, we expected to observe a decrease in similarity at the marsh-upland border. In this case, two measures were chosen. One was Jaccard's index (Mueller-Dombois and Ellenberg 1974) which requires binary data (presence-absence):

$$
\mathrm{ISJ}=\frac{c}{a+b+c} \times 100,
$$


where $c$ is the number of species common to both quadrats, $a$ is the number of species unique to the first quadrat, and $b$ is the number of species unique to the second quadrat. The second was Ellenberg's (1956 in Mueller-Dombois and Ellenberg 1974) modification of Jaccard's index which accepts species quantities:

$$
\text { ISE }=\frac{M c: 2}{M a+M b+M c: 2} \times 100 .
$$

Here, $M c$ is the sum of cover values of species common to both quadrats, $M a$ is the sum of the cover values of the species restricted to the first quadrat, and $M b$ is the corresponding sum for species restricted to a second quadrat. Species noted as present but with negligible cover were assigned a value of 0.25 to preserve their indicator value but minimize their influence.

Graphs of similarity values for adjacent quadrat pairs showed several peaks and troughs reflecting zonal patterns along the elevation gradient (Figure 2). The most elevated trough denoted by 40 percent or greater decrease in similarity, and the next lower trough, were interpreted as the ULM and LTZ, respectively.

\section{Comparison of Methods}

Each quantitative method was applied to a common data set. Twenty-two transects $(12 \%)$ were chosen at random from the 190 sampled by Frenkel et al. (1978). The data were collected from 50 by $50 \mathrm{~cm}$ quadrats. Transects were located with one end well into wetland, the other well into upland, and the orientation parallel to the elevation gradient. Plant species in each quadrat were recorded as to cover class (Daubenmire 1959) except that those with negligible cover were assigned "present" status only. Categorization of plant species as to marsh, upland, etc., was not modified. As LTZ and ULM were calculated by each method, careful note was made of the time and ease of application. ULM identification was stressed because of its direct relationship to jurisdictional questions. ULM was considered to be synonymous with the upper limit of the transition zone.

Data presented in Table 1 reveal close agreement in LTZ and ULM positions obtained by the six methods. ULM for transects 0808 and 1606 was not identified by all methods, suggesting that the transects did not extend far enough to include both marsh and upland quadrats. ULM location agreed within $1.0 \mathrm{~m}$ on 9 of the remaining 20 transects $(45 \%)$ and within $2.5 \mathrm{~m}$ on 13 transects $(65 \%)$. The range of ULM estimates was greatest for transect $1703(25.5 \mathrm{~m})$, but cluster and similarity plots for this transect showed discontinuities at positions in agreement with other methods that could be interpreted as ULM. In general, methods using species classification (five percent, joint occurrence, and multiple occurrence) exhibited low intra-group variability, as did those without species classification.

All methods, with the exception of cluster, involved simple hand calculations. Cluster required a computer. Time differences were small, given basic field data and plant classifications, suggesting that the choice of method should be determined by time available for field work and availability of indicator species lists.

Perhaps the most important result of this comparative treatment was that use of species presence-absence yields ULM positions identical or nearly identical to those requiring species percent cover. Thus, the field effort required to obtain 
Table 1. Lower transition zone limit (LTZ) and upper limit of marsh (ULM) as determined by 6 methods applied to 22 transects from Frenkel et al. (1978). Limits expressed as distance $(m)$ along transect where distance increases from marsh to upland.

\begin{tabular}{|c|c|c|c|c|c|c|c|c|c|c|c|c|c|c|c|c|}
\hline \multirow{2}{*}{$\begin{array}{l}\text { Transect } \\
\text { number }\end{array}$} & \multirow[b]{2}{*}{ Location } & \multicolumn{2}{|c|}{ Five percent } & \multicolumn{2}{|c|}{$\begin{array}{c}\text { Joint } \\
\text { occurrence }\end{array}$} & \multicolumn{2}{|c|}{$\begin{array}{c}\text { Multiple } \\
\text { occurrence }\end{array}$} & \multicolumn{2}{|c|}{ Cluster } & \multicolumn{2}{|c|}{$\begin{array}{c}\text { Similarity } \\
\text { ISJ }\end{array}$} & \multicolumn{2}{|c|}{$\begin{array}{c}\text { Similarity } \\
\text { ISE }\end{array}$} & \multirow{2}{*}{$\begin{array}{l}\text { ULM } \\
\text { Mean }\end{array}$} & \multirow{2}{*}{$\begin{array}{l}\text { ULM } \\
\text { S.D. }\end{array}$} & \multirow{2}{*}{$\begin{array}{l}\text { ULM } \\
\text { Range }\end{array}$} \\
\hline & & LTZ & ULM & LTZ & ULM & LTZ & ULM & LTZ & ULM & LTZ & ULM & LTZ & ULM & & & \\
\hline & OREGON & & & & & & & & & & & & & & & \\
\hline 0105 & Coquille Estuary & 11.0 & 14.5 & 9.0 & 14.5 & 11.5 & 13.0 & 9.0 & 14.5 & 11.5 & 15.5 & 12.5 & 14.5 & 14.4 & 0.8 & 2.5 \\
\hline 1208 & Coos Bay & 16.5 & 19.5 & 16.5 & 21.5 & - & 21.0 & - & 19.5 & - & 21.5 & - & 21.5 & 20.8 & 1.0 & 2.0 \\
\hline 0301 & Alsea Bay & 9.0 & 15.5 & - & 15.5 & 10.0 & 15.0 & 9.0 & 15.5 & 9.0 & 15.5 & 9.0 & 15.5 & 15.4 & 0.2 & 0.5 \\
\hline 0310 & Alsea Bay & - & 13.0 & - & 13.5 & 10.0 & 12.0 & 9.0 & 13.5 & 7.0 & 13.5 & 9.0 & 13.5 & 13.2 & 0.6 & 1.5 \\
\hline 0402 & Yaquina Bay & - & 19.5 & - & 19.5 & 一 & 18.5 & 13.5 & 19.5 & 13.5 & 19.5 & 13.5 & 19.5 & 19.3 & 0.4 & 1.0 \\
\hline 0407 & Yaquina Bay & 4.5 & 19.5 & 4.5 & 19.5 & 7.5 & 19.5 & 1.5 & 19.5 & 10.5 & 19.5 & 10.5 & 19.5 & 19.5 & 0.0 & 0.0 \\
\hline 0704 & Nehalem Bay & 1.0 & 11.0 & 1.0 & 11.5 & - & 8.0 & 7.0 & 15.5 & - & 9.0 & - & 9.0 & 10.7 & 2.7 & 7.5 \\
\hline 0706 & Nahalem Bay & 10.5 & 13.0 & 10.5 & 13.5 & 10.5 & 11.1 & 10.5 & 15.5 & 7.0 & 16.5 & 12.5 & 16.5 & 14.4 & 2.2 & 5.4 \\
\hline \multirow[t]{2}{*}{$07 \mathrm{i0}$} & Nahalem Bay & - & 16.0 & - & 15.5 & - & 15.0 & - & 15.5 & - & 15.5 & - & 15.5 & 15.5 & 0.3 & 1.0 \\
\hline & WASHINGTON & & & & & & & & & & & & & & & \\
\hline 0804 & Willapa Bay & 14.5 & 15.5 & 14.5 & 16.5 & 11.0 & 15.0 & 9.0 & 15.5 & 9.0 & 15.5 & 9.0 & 15.5 & 15.6 & 0.5 & 1.5 \\
\hline 0808 & Willapa Bay & - & - & - & - & 8.0 & - & 5.0 & 15.5 & - & - & - & - & - & - & - \\
\hline 0809 & Willapa Bay & 15.0 & 22.5 & - & 22.5 & 15.0 & 22.0 & 19.0 & 22.5 & 20.5 & 22.5 & 19.0 & 22.5 & 22.4 & 0.2 & 0.5 \\
\hline 0910 & Willapa Bay & 84.5 & 87.5 & - & 87.5 & 63.5 & 87.5 & - & 87.5 & 65.0 & 87.5 & 65.0 & 87.5 & 87.5 & 0.0 & 0.0 \\
\hline 1001 & Willapa Bay & 256.0 & 265.0 & - & 265.0 & 248.0 & 259.0 & - & 259.0 & - & 249.0 & - & 249.0 & 257.7 & 7.2 & 16.0 \\
\hline 1103 & Grays Harbor & 105.5 & 146.0 & 105.5 & 147.5 & 117.5 & 129.5 & 117.5 & 147.5 & 117.5 & 147.5 & 98.0 & 147.5 & 144.3 & 7.3 & 18.0 \\
\hline 1201 & Grays Harbor & 18.5 & 19.5 & - & 19.5 & - & 19.0 & 17.0 & 19.5 & 17.0 & 19.5 & 17.0 & 19.5 & 19.4 & 0.2 & 0.5 \\
\hline 1606 & Thorndyke Bay & - & - & - & - & - & - & - & - & - & 10.5 & - & 10.5 & - & - & - \\
\hline 1610 & Thorndyke Bay & - & 6.0 & 3.5 & 7.5 & - & 3.0 & 一 & 10.5 & - & 10.5 & - & 10.5 & 8.0 & 3.1 & 7.5 \\
\hline 1611 & Thorndyke Bay & 9.0 & 12.5 & - & 12.5 & 6.0 & 12.0 & - & 10.5 & 4.5 & 10.5 & 4.5 & 10.5 & 11.4 & 1.0 & 2.0 \\
\hline 1612 & Thorndyke Bay & - & 21.5 & - & 21.5 & 1.0 & 20.0 & 12.0 & 23.5 & - & 12.0 & 12.0 & 23.5 & 20.3 & 4.3 & 11.5 \\
\hline 1703 & Snohomish Estuary & - & 7.5 & - & 7.5 & 一 & 6.0 & - & 31.5 & - & 31.5 & - & 31.5 & 19.3 & 13.4 & 25.5 \\
\hline 1802 & Oak Bay & - & 26.0 & - & 25.5 & - & 25.5 & - & 25.5 & 10.5 & 25.5 & 19.5 & 25.5 & 25.6 & 0.2 & 0.5 \\
\hline
\end{tabular}


plant cover may not be necessary, and the greatest return might be from utilizing species occurrence only.

\section{Discussion and Recommendations}

The methods evaluated fall into two basic groups. The first comprises five percent, joint occurrence, and multiple occurrence and is characterized by reliance on pre-established lists of wetland and upland indicator species. Botanical expertise is required but, theoretically, a valid ULM determination could be made without in-depth knowledge of wetland ecology.

The second group_cluster, similarity ISJ and similarity ISE-does not require preclassification of plant species. Instead, it is assumed that species are distributed along elevation gradients in such a way as to form groups characteristic of wetland, transition, and upland, and that these groups can be identified objectively. This study suggests that this approach is viable and that results are comparable to those obtained by preclassification methods. Cluster and similarity methods are most sensitive to vegetation patterns and require interpretation based on ecological knowledge, as transect 1703 illustrates. A ULM of $31.5 \mathrm{~m}$ was chosen, but it is likely that a position closer to $7.0 \mathrm{~m}$ as indicated by five percent, joint occurrence, and multiple occurrence would have been the selected ULM, given on-site review. All six methods should be viewed as tools with strong indicator value and, whether classification of plant species is involved or not, the final boundary decision should involve sound ecological judgment.

A general vegetative approach to wetland boundary identification is outlined in Figure 3. If classification of plants is available, the joint occurrence method may be best because it reduces field time and yields results close to the five percent and multiple occurrence methods. If accepted plant classifications are unavailable, as is the present case for most freshwater wetlands, the cluster method or similarity ISJ applied to presence-absence data may provide defensible boundaries and have the added advantage of helping to establish a classification. Even if the requisite information needed to apply the joint occurrence method is available, it is still advisable to employ either cluster or similarity ISJ or both to support the initial decision.

Although a vegetative approach to ULM determination is likely to be satisfactory, in that plant distributions reflect environmental conditions, our present knowledge of physical factors, such as soils and hydrological regimes, across the transition is very limited. It is assumed that certain plants indicate physical conditions of wetland, transition, and upland; but we do not know tolerance limits for species so classified. Research underway at the U.S. Environmental Protection Agency and U.S. Army Corps of Engineers is designed to provide a more holistic treatment of the wetland boundary problem. Physical factors between wetland and upland are being intensively monitored at numerous wetland sites; greenhouse studies are testing species tolerance to various field conditions, such as inundation and soil saturation, and methods are being devised to incorporate both vegetation and physical factors in wetland boundary identification. In the near future, the ability to establish boundaries will be enhanced beyond the sole reliance on vegetation. 


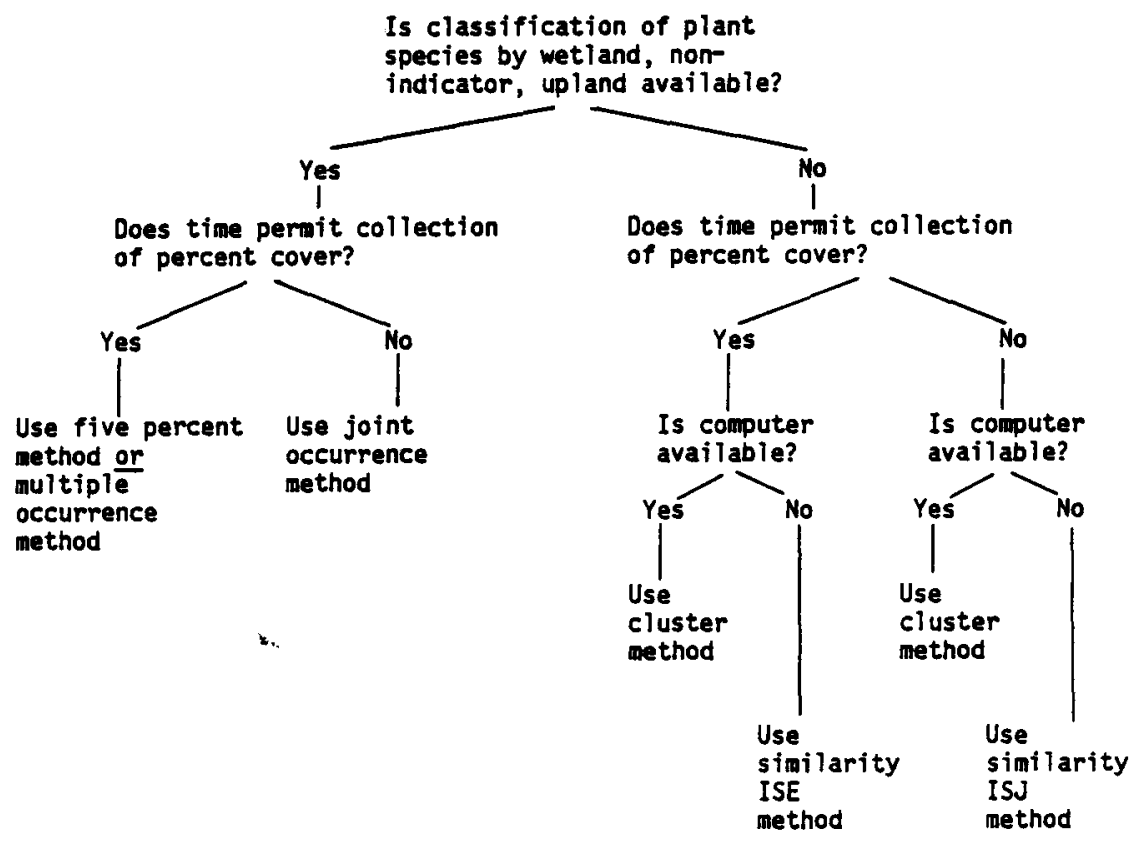

Figure 3. Flow diagram to facilitate choice of vegetation method to determine upper limit of wetland.

\section{Acknowledgements}

We thank Theodore Boss for comments and criticism; Jo Oshiro for help with computer graphics; and Brian Lightcap, Terry Huffman, Robert Frenkel, Porter Reid, David Peters, David Price, and William Sipple for critical review of the draft manuscript.

\section{Literature Cited}

Batten, A. R., S. Murphy, and D. F. Murray. 1978. Definition of Alaskan wetlands by floristic criteria. Report to the U.S. Environmental Protection Agency, Corvallis, Oregon.

Boesch, D. F. 1977. Application of numerical classification in ecological investigations of water pollution. Special Scientific Report No. 77, Virginia Institute of Marine Science, Gloucester Point, Va.

Boon, J. D., D. M. Ware, and G. M. Silberhorn. 1978. Survey of vegetation and elevational relationships within coastal marsh transition zones in the central Atlantic coastal region. Report to the U.S. Environmental Protection Agency, Corvallis, Oregon.

Clifford, H. T., and W. Stephenson. 1975. An introduction to numerical classification. Academic Press, New York.

Darnell, R. M. 1976. Impacts of construction activities in wetlands of the United States. Publ. No. EPA-600/3-76-045. U.S. Environmental Protection Agency, Corvallis, Oregon. 
Daubenmire, R. F. 1959. Canopy coverage method of vegetation analysis. Northwest Sci. 33:43-64.

Fager, E. W. 1957. Determination and analysis of recurrent groups. Ecology 38:586-595.

Frenkel, R. E., and H. P. Eilers. 1976. Tidal datums and characteristics of the upper limits of coastal marshes in selected Oregon estuaries. Report to the U.S. Environmental Protection Agency, Corvallis, Oregon.

Frenkel, R. E., T. Boss, and S. R. Schuller. 1978. Transition zone vegetation between intertidal marsh and upland in Oregon and Washington. Report to the U.S. Environmental Protection Agency, Corvallis, Oregon.

Harvey, H. T., M. J. Kutilek, and K. M. DiVittorio. 1978. Determination of transition zone limits in coastal California wetlands. Report to the U.S. Environmental Protection Agency, Corvallis, Oregon.

Jefferson, C. A. 1976. Relationship of vegetation and elevation at upper and lower limits of the transition zone between wetland and upland in Oregon's estuaries. Report to the U.S. Environmental Protection Agency, Corvallis, Oregon.

Mueller-Dombois, D., and H. Ellenberg. 1974. Aims and methods of vegetation ecology. John Wiley, New York.

National Ocean Survey (NOAA). 1975. The relationship between the upper limit of control marshes and tidal datums. Rockville, National Ocean Survey report to the U.S. Environmental Protection Agency, Corvallis, Oregon.

Odum, E. P. 1961. The role of tidal marshes in estuarine production. The Conservationist 15:12-13.

Teal, J. M. 1962. Energy flow in the salt marsh ecosystem of Georgia. Ecology 43:614-624. 